The volcanic region around Larderello has been but scantily explored so far; it is believed, however, that all the Tuscan soffioni have one common origin.

The choice of condenser or free exhaust turbines is an economic question involving careful study. The latter have advantages from the point of view of economy in installation, upkeep and running costs, but they also have a higher steam consumption.

There is little that is new in the production of boric acid at Larderello, which is putting on the market a crude acid of 95 per cent purity; this industry is to-day a highly competitive one consequent on the discovery of vast quantities of boric acid at Searles Lake, California, and elsewhere.

The steam contains about 6 per cent by weight of gas, of which about 92 per cent is carbon dioxide. A large plant has been erected for its separation and compression, both to liquid and solid carbon dioxide, both products which have increasing importance for refrigeration and other purposes.

Work is in hand also to separate the sulphur dioxide for the production of hyposulphites and sulphites, and further, the methane which, if obtained sufficiently cheaply, can be made the source from which to obtain numerous synthetic carbon derivatives. It is projected even to obtain the rare gases, including helium, which, it is believed, is present in sufficient proportions to justify its separation.

To those with vision, the whole achievement is a very remarkable one. The soffioni steam is being exploited in the most complete manner, both on account of its thermal and of its chemical value : to draw from the earth a source of power and at the same time obtain from it an antiseptic, a fertiliser, a refrigerant, a photographic chemical, an illuminating gas as well as the rare gases, makes the inferno a source of wealth far richer than Aladdin's Cave. The exploitation of such riches is a task which is taxing to the full the ingenuity and ability of Italian engineers and chemists, who are proving well fitted for their honourable task. There can be no more convincing example of a saying of Sir Oliver Lodge's which Prince Conti quoted: "There is lavishness in Nature but no waste."

The organisation under the leadership of Prince Conti has been built up as the result of full recognition of the vital importance of what pure or fundamental research can contribute towards the better utilisation of natural resources : it was also emphasised how completely it has enjoyed the support of the Italian National Government. Great have been the ravages wrought in Italy by volcanic disturbances; perhaps they may be to some extent equated in the future by the benefit arising out of the harnessing of their forces in the manner described.

E. F. A.

\title{
Leicester Meeting of the British Association
}

GROM the point of view of the British Association, Leicester is a changed city since the meeting in 1907. When the Association meets there on September 6-13, a whole range of fine buildings will be found to have become available since 1907 for its use. The Wyggeston Girls' School, where the reception room, offices, and one of the sections will be established, must be one of the most notable buildings of its kind in the country. The University College, though it occupies an old building, was not established at the time of the last meeting : it now offers accommodation for sections and the inspiration which, for such an occasion as an Association meeting, is afforded by the mere existence of such an institution. The Wyggeston Boys' School adjoins it. The De Montfort Hall is admirably suited for the inaugural meeting. These and other available buildings have the advantage of being situated conveniently to the centre of the city but outside it, a consideration making for the comfort of audiences as external noise is avoided, and access is easy.

Among the many points of interest for scientific visitors in the area for which Leicester is the centre -and they are far more numerous than is realised, probably, by most people-Loughborough College must be specially mentioned. This institution, the outcome of engineering and kindred activities during the War, is of peculiar interest in itself. But not only this: it also offers, what Leicester itself does not, save for the purposes of the secretariat and a few other members, a remarkably fine series of hostels. Living accommodation in hostels during Association meetings is found always to be popular among visiting members, and those who like it need not be discouraged by the distance of thirteen miles from Leicester, for rail and road communications are easy and quick.

The preliminary programme just issued and obtainable from the Association offices at Burlington House, Piccadilly, London, W.1, gives details of the foregoing arrangements and much else besides. The city itself is seen to be well provided with hotels and private hotels convenient to the meeting-rooms. The list of possible excursions and visits indicates the wide scientific interests of the locality. Charnwood Forest, Derbyshire, the Fen Country, the Warwickshire area, are all within reach. Many industrial, agricultural, and educational establishments are to be seen, the last including University College, Nottingham.

The president, Sir Frederick Gowland Hopkins, combining for the year the onerous duties of the chairs of the Royal Society and of the Association, will deal in his inaugural address with the chemical aspects of life. As for the programme of scientific transactions at large, the Association cannot be 
accused of neglecting current affairs of public interest. The policy of tackling such topics as the gold standard and increasing the supply of gold, a national educational system, the evolution of terrestrial life, industrial physics, and others which find place in the present programme, has its rewards, and occasionally something more. The introduction of some pregnant subject of public concern has sometimes led people to ask why the Association does not do more than merely talk about them : a few were disappointed last year when one noteworthy pronouncement was not followed by immediate action; and quite lately a newspaper correspondent demanded that the Association should not merely formulate a remedy for unemployment, but also apply it. Such action may be scarcely within the Association's powers.

On the other hand, the effort indicated in the programme and by documents issued along with it, to bring the publications of the Association more widely into notice, is an effort, deserving of all support, toward the removal of a weakness. The Association, though supplying to the ephemeral press and to specialist publications a vast range of scientific material, has never yet itself become as effective a recording instrument as stronger public support might make of it.
The Association, from the point of view of those who must raise local funds for its reception, is a less exacting guest than it used to be, and it is right and indeed necessary that this should be so. The programme gives amply sufficient evidence of the hospitality which Leicester intends to offer, including as it does a reception to be given by the Lord Mayor (Councillor Arthur Hawkes), another by the Leicester Literary and Philosophical Society, and a garden party by the University College. Nor, as already suggested, will Leicester fail in the heavy task of finding meeting-roomsfor in that matter the Association does not moderate its demands. Yet, when sections ask to form departments and run two or three meetings at once, or propose to arrange cinematograph or other demonstrations, it would be ungenerous to deny opportunities to the devoted bands of workers who arrange the sectional programmes for the honour of science and the Association, and maintain, as in the present programme they certainly do maintain, the high standard of interest which they and their predecessors have set up. Participation in the Leicester meeting may be confidently recommended, for the sake not only of the Association, but also of Leicester.

\section{Obituary}

Pror. W. C. Unwin, F.R.S.

$\mathrm{T}^{\circ}$ understand the great debt which engineering science owes to the late Prof. William Cawthorne Unwin, it must be remembered that it was in 1856 that he started on his engineering career and that it is sixty-five years since he first began to teach engineering. Born at Coggeshall in Essex, on December 12, 1838, Unwin had all the advantages of being brought up in academic surroundings, for his father, Dr. William J. Unwin, was principal of Homerton College.

On leaving school in 1856, Unwin was fortunate in being apprenticed to Sir William Fairbairn, an engineer and a most distinguished research worker in engineering science. As might be expected in those early days of experimental engineering, the work was of a most varied nature and this had an important bearing on Unwin's later work. Elaborate researches were carried out on the specific volume of saturated steam, and on the effects of repeated loading of plate girders, the most arduous part of the experimental work devolving on the young and enthusiastic Unwin. But, though interesting and instructive, engineering research was not very remunerative and, no doubt, Unwin was recalling his own experiences when in one of his latest addresses, he deplored the fact that the importance of engineering research was not even then recognised by those who had charge of great engineering undertakings. Working at engineering research all day Unwin found time at night to continue his studies, and in 1860 took the degree of B.Sc. at the University of London, where he played so important a part many years later when the course for a degree in engineering was being arranged.

In 1862, theoretical and practical training completed, Unwin became manager at the works of Messrs. Williams at Kendal where the manufacture of Thomson's new vortex turbine had been begun. Then, in 1867, he was appointed manager of the engine department of the Fairbairn Engineering Company. He remained, however, only a short time with this firm, as in 1868 he was made instructor in marine engineering in the Royal School of Naval Architecture, and in 1872 he was appointed professor of hydraulics and mechanical engineering at the Royal Indian Engineering College, Coopers Hill, which position he held until 1884. In 1877 was published his textbook on the "Elements of Machine Design", probably the most widely known of all his books and deserverly so. He wrote as a teacher who gave his readers the necessary information acquired either by his own research or by that of others. Clear and concise explanation was his strong point, and so no textbooks are required to explain Unwin.

Unwin's great success as the teacher of young engineers became possible when in 1884 he was appointed professor of civil and mechanical engineering in the newly established City and Guilds Central Technical College. London was at last to have a college in which engineering science could be taught systematically, in suitable laboratories, equipped with all the necessary plant and 